\title{
RODRIGO FACIO BRENES (1917-1961). ANOTACIONES DE SU PERFIL PERSONAL ${ }^{1}$
}

\section{RODRIGO FACIO BRENES (1917-1961). ANNOTATIONS OF HIS PERSONAL PROFILE}

\section{Jorge Enrique Romero Pérez *}

\author{
En memoria de Rodrigo Facio Brenes (1917-1961). \\ Agradecimientos: a su esposa Leda Fernández Vaglio (fallecida en abril de 2012) \\ y a sus hijas Dagmar, Tatiana y Gabriela \\ por haberme dado el privilegio de tener acceso al archivo personal de Don Rodrigo.
}

\section{RESUMEN}

Este artículo versa sobre la presentación de parte del contenido inédito del archivo personal de Rodrigo Facio Brenes. El perfil que proporciona este material muestra un ser humano con valiosos rasgos profesionales, académicos, periodísticos, de investigación, que hacen de él un Maestro.

PALABRAS CLAVE: PROFESOR * INVESTIGADOR * PENSADOR * ECONOMÍA * HISTORIA * SOCIOLOGÍA * CAPILLA * BUROCRACIA

\section{ABSTRACT}

This article turns on the presentation on behalf of the unpublished content of personal file of Facio Brenes. The profile that provides this material a human being shows with valuable professional, academic, journalistic features, of investigation, that make of him a Master.

KEYWORDS: PROFESSOR * RESEARCHER * THINKER * ECONOMY * HISTORY * SOCIOLOGY * CHAPEL * BUREAUCRACY

El lunes 6 de junio de 2011, en el Auditorio Abelardo Bonilla de la Escuela de Estudios Generales, la Vicerrectoría de Investigación de la Universidad de Costa Rica organizó un homenaje a Don Rodrigo Facio Brenes, en este, una de las hijas de Don Rodrigo, Dagmar Facio Fernández, me invitó a decir unas palabras sobre su papá, lo cual agradezco. La exposición oral que hice ha servido de base para este ensayo, que el director de la Revista de Ciencias Sociales, Dr. Daniel Camacho Monge, presente en ese acto, me invitó a elaborar por escrito para ser publicado en esta revista. Mis agradecimientos para él y para la editora de dicha revista, María Fernanda Arguedas Abarca.

* Sistema de Posgrado en Derecho, Universidad de Costa Rica (UCR). Revista de Ciencias Jurídicas de la Universidad de Costa Rica y del Colegio de Abogados.

jorgerp10@gmail.com / jorgerp9@yahoo.com 


\section{INTRODUCCIÓN}

El que fue Rector de la Universidad de Costa Rica, Rodrigo Facio Brenes, me llamó fuertemente la atención, lo cual me motivó a leer en profundidad y con detenimiento, sus obras, discursos, ensayos, artículos periodísticos, en fin, la globalidad de su pensamiento.

A la vez que profundizaba en su pensamiento y en su obra, publiqué un conjunto de escritos, en torno a su figura y su papel en la historia de Costa Rica.

Así, publiqué: La social democracia en Costa Rica (San José: EUNED, 1982); Contribución a la comprensión del Estado moderno en Costa Rica: el reformismo político y el pensamiento de Rodrigo Facio Brenes (San José: Facultad de Derecho, Universidad de Costa Rica, 1976); En el vigésimo aniversario de la muerte de Rodrigo Facio Brenes. Presentación y edición (San José: Facultad de Derecho, Universidad de Costa Rica, 1981); Acción Demócrata. Orígenes del Partido Liberación Nacional. De León Cortés a José Figueres (San José: Editorial Nueva Década, 1983); Presentación y edición a la obra póstuma de Rodrigo Facio Brenes. Latinoamérica en la encrucijada. Los dogmas económicos ante las realidades económicas (San José: Editorial Universidad de Costa Rica, 2009). Precisamente, con el estudio preliminar (páginas 4 a 94) y edición de esta obra, siendo Miembro de Número de la Academia de Historia y Geografía de Costa Rica, obtuve la categoría de Miembro de Silla de esta organización.

En lo que corresponde a este artículo, se presentaran una serie de elementos tomados de su archivo personal. Los documentos de este archivo son inéditos; de tal modo que por primera vez se hacen públicos; con la salvedad del libro de Don Rodrigo Facio Brenes: Latinoamérica en la encrucijada. Los dogmas económicos ante las realidades económicas, al cual le hice una presentación y realicé las labores de edición.

El orden en que se presentan aquí es convencional $y$ ha sido de mi responsabilidad.

Este archivo, que su autor confeccionó, refleja su carácter y personalidad. Muy ordenado, detallista, claro en sus objetivos, don
Rodrigo muestra una obra personal, humana y profesional en construcción, en evolución.

\section{CONTENIDO DE SU ARCHIVO PERSONAL}

El contenido de este archivo personal que fue construyendo, está contenido en tomos encuadernados sencillamente.

\section{A) SELECCIÓN DEL ARCHIVO PERSONAL}

$\diamond \quad$ Varios curriculum vitae suyos escritos en inglés y español.

$\diamond \quad$ Cartas personales e institucionales.

$\diamond \quad$ Telegramas recibidos, sobre diferentes temas.

$\diamond \quad$ Tarjetas de cumpleaños de sus hijas y dibujos que ellas hacían cuando niñas.

$\diamond \quad$ Recortes de periódicos, de una variedad amplia de temas.

$\diamond \quad$ Conferencias $y$ ensayos hechos a mano $y$ en su máquina de escribir marca Olympia, con anotaciones al margen $y$ encima de los renglones, dado que escribía a doble espacio, para tener oportunidad de hacer las anotaciones a mano, antes de confeccionar la versión última.

$\diamond \quad$ Documentos de pedidos de revistas $y$ de libros al extranjero, incluyendo los comprobantes de pago y las facturas pro-forma y definitivas (ejemplos: Revista Trimestre Económico, del Fondo de Cultura Económica, de México; Revista Política, de Venezuela).

$\diamond \quad$ Temarios de los cursos que dio en la Universidad de Costa Rica, desarrollo de esos temas, a los cuales se acostumbraba llamarlos "tesis 1, 2, 3, etc." Se observa que fue un proceso de anotaciones a mano y en otras partes, hechas a máquina, como un proceso de elaboración constructiva. Daba la impresión, que por ello todo estaba en elaboración.

Se notaba en su forma de trabajar y de construir su pensamiento en ciencias sociales (Derecho, Economía, Educación, Sociología, Antropología, Historia, Psicología, etc.), la fuerte y permanente creación de la investigación y del pensamiento. 
Como había la posibilidad de graduarse como abogado y notario, tuvo el título de licenciado en este campo (en 1941) en la Universidad de Costa Rica. En las demás ciencias sociales fue autodidacta y constructor. Su pensamiento fue pionero en este campo de las ciencias sociales, con la modalidad de elaborar sus ideas, entrelazando y mezclando sus estudios, investigaciones y conocimientos en Sociología, Historia, Derecho, Economía, Psicología, Filosofía, etc. Su formación como jurista fue una base desde la cual, levantó su obra multidisciplinaria e interdisciplinaria.

Fue un pensador crítico, creativo y con una permanente inquietud de investigación.

$\mathrm{Su}$ labor como burócrata en diversas organizaciones, como bancos estatales y la Universidad de Costa Rica, no fue un obstáculo o impedimento para realizar su obra, al contrario, ello le proporcionó experiencia, conocimiento y estímulo para investigar y escribir.

$\diamond \quad$ Documentos que prueban que solicitaba y recibía documentos y publicaciones, por ejemplo, del Banco Mundial, del Fondo Monetario Internacional, la Comisión Económica para América Latina, Facultad Latinoamericana de Ciencias Sociales.

$\diamond \quad$ Los recortes de periódico de La Nación, La República, La Prensa Libre, El Diario de Costa Rica, son de una gran variedad de temas; incluyendo, los artículos que le publicaron sobre temas económicos, políticos, etc.

$\diamond \quad$ El presidente abogado Mario Echandi Jiménez (1958-1962) convocó a una reunión de ciudadanos o de notables, el 18 de junio de 1959. Entre ellos estaba don Rodrigo. Hubo un debate con Jaime Solera Bennett, en ocasión de las reuniones de esta junta (La Nación, junio 1959).

$\diamond \quad$ En esos recortes hay constancia de polémicas o debates con personas jurídicas $y$ con personas físicas, sobre diversos temas en Derecho, Economía y Política.

$\diamond \quad$ La Nación del 31 de julio de 1959, da información sobre el inicio de la relación de la Universidad de Kansas y la Universidad de Costa Rica.

Nota del autor: Charles L. Stanfifer y María Eugenia Bozzoli Vargas publicaron el libro La Universidad de Costa Rica y la Universidad de Kansas: una extraordinaria relación de cooperación académica, Editorial Universidad de Costa Rica, 2010. Hay también una versión en inglés. Este convenio de cooperación se firmó en 1959 y sigue vigente al presente.

Carta que le manda don Rodrigo al Dr. Kenneth Holland, miembro de la Comisión de Gobierno de Estados Unidos, respecto de las relaciones de este país con América Latina (AL); señalando que USA debe abandonar la idea de imponer su política económica a los países de AL (La Prensa Libre, 6 y 7 de enero de 1959).

$\diamond \quad$ Don Rodrigo firma, con otros políticos e intelectuales de América Latina, un documento de apoyo a la doctrina de la libre determinación de los pueblos, en el contexto de la Revolución Cubana ( $L a$ Nación, 19 de abril; La República, 16 de abril, Diario de Costa Rica, 20 abril, todos de 1960).

$\diamond \quad$ Documentos de las certificaciones de las notas que obtuvo como alumno del Liceo de Costa Rica: primer año, 1931; segundo año, 1932, tercer año, 1933, cuarto año, 1934 y quinto año, 1935.

$\diamond \quad \mathrm{Su}$ madre Rosario Brenes Mata firmó todas esas certificaciones de notas.

$\diamond \quad$ Documentos que prueban las conferencias que don Rodrigo dio en la UCR y en otros lugares.

$\diamond \quad$ Información de los viajes al exterior, de carácter académico oficial.

$\diamond \quad$ En Repertorio Americano, Nro. 1181 del 20 de enero de 1958, don Rodrigo y otros académicos y políticos de América Latina, publican un manifiesto: 
La conciencia de América: las nuevas generaciones unidas a todo lo largo de nuestra América, como la llamó José Martí, tienen una clara misión que cumplir: la segunda independencia afirmada en la vigencia de las libertades.

$\diamond \quad$ Discursos que pronunció y programas de inauguración de las diversas Escuelas y Facultades de la UCR.

$\diamond \quad$ Telegramas recibidos de felicitación cuando lo nombraron Rector en 1952, 1954 y 1958.

$\diamond \quad$ El 18 de setiembre de 1952 (El Diario de Costa Rica) decía don Rodrigo que el problema fundamental de la Universidad es que es una universidad a medias.

$\diamond \quad$ Certificados de participación en congresos, seminarios y conferencias nacionales e internacionales.

$\diamond \quad$ Hay ensayos de diverso tamaño, a máquina y a mano, sobre temas de Sociología, Historia nacional e internacional, Política, Economía, Filosofía, haciendo anotaciones a mano y a máquina, con las citas bibliográficas respectivas.

$\diamond \quad$ Comentarios a libros en esas ciencias sociales, ya sea al libro en general o a ciertos capítulos; anotaciones hechas a mano y a máquina marca Olympia.

$\diamond \quad$ Correspondencia recibida y enviada, de carácter personal e institucional.

$\diamond \quad$ Pago de suscripciones de revistas extranjeras, en francés, ingles y español; también documentos que prueban el pago de libros en esos idiomas que solicitó y recibió.

\section{CURSOS UNIVERSITARIOS}

$\diamond \quad$ En los cursos que dio Moneda, crédito y banca, Doctrinas económicas, Filosofía del derecho, por ejemplo, hacía el temario o programa, redactaba las tesis y citaba la bibliografía respectiva.

$\diamond \quad$ Hay notas sobre un curso de Sociología, el temario y la respectiva bibliografía.

$\diamond \quad$ En 1959, redacta los programas o tesiarios de los cursos Economía centroamericana y Principios de Economía, con su respectiva bibliografía.

$\diamond \quad$ En 1942, redacta el programa del curso Economía Política con su bibliografía y desarrolla el tesiario o el contenido de esta materia.

$\diamond \quad$ En 1943, 1946, 1951 y 1952 redacta las tesis, el temario del curso Moneda, crédito y banca, con su bibliografía.

$\diamond \quad$ Discursos de bienvenida a los estudiantes de cada carrera UCR, con anotaciones a mano y a máquina; así como, a los graduados que se marchaban.

$\diamond \quad$ Presentación y palabras respecto de personas importantes que visitaban la UCR (visitantes distinguidos Felipe Herrera, Eduardo Couture, Víctor Raúl Haya de la Torre...).

$\diamond \quad$ Cartas de personas pidiendo becas para sus hijos, nombramientos en la UCR, etc.

$\diamond \quad$ Carta del 17 enero de 1959 de la abogada Virginia Martén de Coto, de agradecimiento por su colaboración financiera al Centro Helen Keller, para ciegos en Desamparados.

$\diamond \quad$ Documentos de la Tributación Directa donde consta que está al día en el pago del impuesto de la renta (por ejemplo: de la década de los años 50).

DOCUMENTOS SOBRE SALARIOS COMO RECTOR AÑOS DE 1952 A 1959

TABLA 1

SALARIOS COMO RECTOR SEGÚN AÑO

\begin{tabular}{lc}
\hline AÑO & SALARIO EN MILES DE COLONES \\
\hline 1952 & 1300 \\
1953 & 2000 \\
1954 & 2200 \\
1955 & 2400 \\
1956 & 2600 \\
1957 & 2800 \\
1958 & sueldo presupuestado \\
1958 & sueldo aceptado por RFB \\
\hline
\end{tabular}


$\diamond \quad$ En el Acta No. 905 del 28 de octubre de 1957, artículo 41, del Consejo Universitario, el Rector se retira de la sesión, dado que se tratará del aumento de su sueldo. Se aprobó que se autoriza a la Comisión de Presupuesto para que en 1958, se fije el sueldo del Rector en 4000 colones.
En el Acta No. 907, artículo 31, del 4 de noviembre de 1957, el Rector Facio manifestó que no aceptaría ese aumento de 4000 colones, mientras estuviera ejerciendo otras funciones fuera de la Universidad, recordando sus palabras de 1953.

\begin{tabular}{ccc}
\hline AÑO & TIPO DE SUELDO & TOTAL \\
\hline 1959 & Sueldo presupuestado & 4000 \\
1959 & Sueldo ajustado por reglamento de personal & 3466,65 \\
1960 & Sueldo presupuestado & 3500 \\
1960 & Sueldo ajustado por reglamento de personal hasta mayo inclusive & 3033,40 \\
\hline
\end{tabular}

$\diamond \quad$ Documentos solicitando a un librero en Nueva York, Samuel Ambarás (6 de agosto de 1959), libros en inglés de Federico Engels, John Stuart Mill, Lenin, Stalin, Eugenio Varga (economista húngaro, 1879-1964). Estos libros, con excepción de los dos de Varga, fueron despachados por el librero el 1 de setiembre de 1959 y nota del 3 de este mes y año:
Prof. Rodrigo Facio

Rector de la Universidad de Costa Rica

Ciudad Universitaria Costa Rica

Engels: The Condition of the Working Class.

Lenin: The Development of Capitalism in Russia.

Mill: Principles of Political Economy, 2 vols.

Stalin: Marxism and the National and Colonial Question.

La solicitud de Facio Brenes fue:

Ciudad Universitaria.

6 de Agosto de 1959.

Señor Samuel Ambarás

Box 138, Hamilton Grange Station,

New York. 31, NY, USA.

Estimado señor:

Se tiene interés en adquirir estos libros:

ENGELS, Friedrich. The Condition on the Working Class in England

LENIN. The Development of Capitalism in Russia.

MILL, J.S. Principles of political Economy. 2 vols.

STALIN. J.Marxism and the National and Colonial Question

VARGA, E. The Decline of Capitalism

VARGA, E. Two Systems. Socialist Economy and Capitalist 
$\diamond \quad$ Carta al Consejo Universitario del 14 de octubre de 1960, por la cual informa que el Banco Interamericano de Desarrollo, lo ha contratado como asesor de su división de asistencia técnica, razón por la cual se retira de la Universidad. Señala que en 1952, cuando se le nombra como Rector, propuso una plataforma de trabajo, que considera que se ha cumplido y que por ello, tiene derecho a un legítimo relevo.

Las empresas Fondo de Cultura Económica de México y la Editorial Universitaria de Chile, se ofrecen para publicarle el libro que Rodrigo Facio está preparando: América Latina en la encrucijada.

$\diamond \quad$ Cartas de Eduardo Castro Le-Fort, gerente de la Editorial Universitaria de Chile, del 16 de mayo de 1960 y del 16 de noviembre de 1960. Cartas de Rodrigo Facio agradeciendo ese ofrecimiento de 27 de mayo de 1960 y del 16 y 23 de noviembre de 1960 .

$\diamond \quad$ Carta del Director del Fondo de Cultura Económica, Arnaldo Orfila Reynal, del 24 de febrero de 1960 y cartas de Rodrigo Facio, dando las gracias por ese ofrecimiento, del 4 de marzo y 16 de noviembre de 1960 .

$\diamond \quad$ Nota del inventario del mobiliario de la oficina de la Rectoría del 5 de enero de 1961, de la Sección de Inventarios de la Oficina de Administración Financiera.

$\diamond \quad$ Carta de Rodrigo Facio al Arzobispo de Costa Rica, Monseñor Dr. Carlos Humberto Rodríguez, del 7 de enero de 1961, en la cual le dice que en vista de su retiro de la Universidad, le expresa su profunda gratitud por las consideraciones que siempre ha tenido, para la Universidad y para su persona, durante su paso por la Universidad. Además, pone en manos del Arzobispo una acción de su propiedad sobre la Clínica Católica de la Purísima SA, para que disponga como lo crea más conveniente para los intereses de la Iglesia.
Carta de don Rodrigo al Dr. Frank D. Murphy, Canciller de la Universidad de
California, en Los Angeles, el 29 de octubre de 1960, dándole las gracias por el ofrecimiento del Dr. Murphy para que Rodrigo Facio fuera profesor visitante en esta Universidad.

$\diamond \quad$ Carta de Don Rodrigo del 25 de noviembre de 1960 a Iván Antonio Marín, Secretario del Comité Ejecutivo Cantonal de Cañas, Guanacaste, en la cual don Rodrigo le dice que él no es pre-candidato del Partido Liberación Nacional (PLN), ya que sus funciones en la Universidad, le inhiben para tomar participación en la política electoral. Este dirigente político le mandó una carta a Facio Brenes, el 21 de noviembre de 1960, en la cual le comunica un acuerdo de los Comités cantonales del PLN de Escazú y de Cañas, a los pre-candidatos Dr. Raúl Blanco Cervantes, don Rodrigo Facio Brenes, Lic. Daniel Oduber Quirós $y$ don Francisco Orlich Bolmarcich.

Nota de autor: En este punto hago la observación que el Presidente de la República en el período 1962 a 1966, fue el señor Francisco Orlich (1907-1969).

$\diamond \quad$ Correspondencia cruzada con funcionarios del BID, en ocasión de ingreso como funcionario para enero de 1961. Proceso cartular e informativo que abarca los meses de abril a diciembre de 1960 .

De este conjunto de notas y cartas, seleccionamos estas:

$\diamond \quad$ Carta de Felipe Herrera, Presidente del BID a Rodrigo Facio del 1 de setiembre de 1960, por la cual se le ofrece el nombramiento como Consultor en la División de Asistencia Técnica en los aspectos sociales de los programas de desarrollo económico en América Latina, especialmente en relación con la vivienda de interés social y reforma agraria. Siendo la remuneración anual de $\$ 18000$.

$\diamond \quad$ Carta de Jorge Hazera, Jefe de la División de Administración del BID, ratificando lo 
dicho por Felipe Herrera, del 9 de setiembre de 1960 .

$\diamond \quad$ Felipe Herrera, por carta de 26 de setiembre de 1960, que desea decirle lo contento que está por haber aceptado el nombramiento.

$\diamond \quad$ Carta de Jorge Hazera, Jefe de la División de Administración del BID, del 30 de setiembre de 1960, por la cual le informa que el nombramiento de Rodrigo Facio es por tiempo indefinido, una vez completado un plazo inicial de un año, que es el período reglamentario de prueba.

$\diamond \quad$ Por carta del 28 de octubre de 1960, Felipe Herrera, Presidente del BID hace el ofrecimiento formal $y$ oficial del puesto de consultor; firmando Rodrigo Facio en el mismo documento esa aceptación formal, con fecha 7 de noviembre de 1960 .

$\diamond \quad$ Destaco en su archivo personal una copia del Manifiesto Comunista de Carlos Marx y Federico Engels, escrito a máquina, con notas y con renglones subrayados.

\section{TEMA DE LA CONSTRUCCIÓN DE LA CAPILLA CATÓLICA EN LA CIUDAD UNIVERSITARIA}

Me refiero a este tema del movimiento de profesores y estudiantes de la Universidad de Costa Rica, con la Juventud Universitaria Católica (JUC); cuyo objetivo fue el de construir una capilla católica dentro del campus universitario.

Se citan varias actas de sesiones del Consejo Universitario de los años 1953 a 1956, documento del abogado de la Universidad, intervenciones de la Contraloría General de la República, documentos de la JUC y por supuesto, el argumento en el pleno del Consejo Universitario, el 26 de octubre de 1953, del Rector Rodrigo Facio Brenes, expresando su disconformidad con la citada construcción, que se cita de inmediato:

\section{A) RAZONAMIENTO DEL VOTO DE DON RODRIGO CONTRARIO A EDIFICAR UNA CAPILLA CATÓLICA DENTRO DEL CAMPUS DE LA CIUDAD UNIVERSITARIA}

El señor Rector Rodrigo Facio Brenes, quien razona su voto de la siguiente manera (acta de la sesión Nro. 96 del Consejo Universitario del 26 de octubre de 1953):

"En principio no encuentro objeción para acordar la erección de una capilla, dedicada al culto católico, en la Ciudad Universitaria que estamos comenzando a levantar. La existencia de un templo religioso en el campus nada implica ni nada quiere decir contra los principios fundamentales de la Universidad: autonomía docente y cultural e irrestricta libertad de cátedra. Señalar un sitio donde los estudiantes y profesores podrán concurrir a recogerse espiritualmente, en función de ideas religiosas que son las de la mayor parte de ello, no denota que la Universidad tome partido confesional ni que esté renunciando a la libertad fundamental para discutir todas las ideas, todas las filosofías, todos los credos, ni impidiendo a ninguno de sus integrantes el hacerlo. Si se me demostrara que la existencia de una Capilla lleva implícita la destrucción de la autonomía universitaria, o algún peligro para la libertad de cátedra, o alguna lesión para la libertad, que la Constitución Política garantiza para todos los habitantes del país, de creer o no creer en Dios o de adorarlo cada uno a su modo; si se me demostrara cualquiera de esas cosas yo estaría naturalmente, $y$ también por principio, contra la idea de la Capilla, porque como costarricense y como funcionario público estoy en la obligación de velar por el mantenimiento de los principios filosóficos y políticos en que se basa la Nación, y más profundamente porque, como hombre, estoy convencido - al margen de mis personales convicciones religiosas y políticas- de que en la libérrima discusión de todas las ideas descansa el progreso científico y la posibilidad de que todos los hombres sean respetados en su dignidad individual.

Como no se me ha demostrado ninguno de esos peligros, ni creo que puedan demostrarse, estoy en principio de acuerdo con la erección de la Capilla.

Sin embargo, como es mi obligación velar también por el orden y la tranquilidad de la institución; como sé que hay en la Universidad quienes objetan, con razones que no comparto pero que respeto, la erección de la Capilla; como no ignoro que toda discusión en que se involucre algún elemento religioso, 
puede dar lugar a fricciones, extremismos y resentimientos; como la cultura nacional en este aspecto no está tan avanzada como lo está dentro de algunos pueblos, como los sajones, donde la tolerancia y la comprensión son virtudes altamente desarrolladas; como, en fin, la erección de la capilla, con ser como lo es una idea aceptable para mí, no aparece sin embargo como una necesidad ineludible, ya que la zona de la Ciudad Universitaria se halla tan cercana a San José y, en el propio San Pedro, al lado de ella, existe una Iglesia católica, me inclino, por que llamaría una razón práctica o pragmática, a votar desfavorablemente la solicitud para erigir la Capilla en la Ciudad Universitaria.

Deseo dejar constancia de que tanto mi voto, como los argumentos que lo abonan, son el fruto de una cuidadosa meditación de mi parte, $y$ que he pretendido actuar, como siempre procuro hacerlo cuando actúo como Rector y Presidente del Consejo Universitario, no guiado por mis simpatías o mis preferencias, sino por lo que me ha parecido más conveniente para la Universidad".

En este aspecto, haría la observación, de que a lo largo de mis más de 50 años de pertenecer a la Universidad de Costa Rica (como estudiante, como docente e investigador), he comprobado como en algunas oficinas o espacios universitarios, se han realizado expresa y manifiestamente, actividades religiosas católicas, con los iconos o imágenes respectivas. Visiblemente $y$ de modo publicitado, no he comprobado malestar o desaprobación expresa y manifiesta, de otros grupos religiosos o no creyentes, respecto de esta costumbre de culto, realizada no oficial o institucionalmente, sino llevada a cabo por alumnos o empleados universitarios.

El hecho comprobado es que la capilla católica o de otras religiones, no se llegó a construir dentro del campus de la Universidad de Costa Rica.

Por mi parte, comparto la exposición que hizo el Rector Facio Brenes.

\section{B) POSICIÓN DE LA JUVENTUD UNIVERSITARIA CATÓLICA, JUC, SOLICITANDO LA CONSTRUCCIÓN DE LA CAPILLA CATÓLICA}

Del sector de profesores y estudiantes que argumentaron a favor de la construcción de la capilla católica dentro del recinto de la
Universidad de Costa Rica, considero que el grupo que propuso ideas interesantes y polémicas fue la Juventud Universitaria Católica, ante el Consejo Universitario de la UCR.

Estas ideas católicas, cobran vigencia para el debate ahora (2012), que se polemiza sobre el Estado laico en Costa Rica, tomando en cuenta - entre otros aspectos- la presencia de dos pastores protestantes (cristianos no católicos), representando a dos partidos políticos — cada uno- en el Poder Legislativo:

Justo Orozco Álvarez del Partido Renovación Nacional y Carlos Avendaño Calvo del Partido Restauración Nacional.

Del debate en torno a esta temática rescato estas publicaciones: "la laicidad del Estado", artículo de Marco Feoli, publicado en $L a$ Nación, el jueves 5 de julio de 2012, pág. 25A y el artículo de Kattya Castro Flores, "Por un Estado laico y en defensa de la libertad de cultos", Diario Extra del viernes 6 de julio de 2012.

$\diamond \quad$ Acta de la sesión del Consejo Universitario. No. 97 del 2 de noviembre de 1953

"San José, 11 de julio de 1953.

Sres. Consejo Universitario.

S.S. M.M.

Estimado señor Rector y señores Decanos:

La Juventud Universitaria Católica inició una campaña pro-Capilla Universitaria que ya Ustedes conocen, acompañamos los pliegos con los resultados y un pequeño estudio sobre su posible significado.

Esperamos que este bello proyecto cuente con la aprobación de ese Consejo y aprovechamos la oportunidad para agradecer de todo corazón el estímulo que hallamos de parte de los señores Decanos, y en especial del señor Rector, al iniciar nuestra campaña, cuando aún no sabíamos que el resultado que obtendríamos sería tan halagador. Muchas gracias por ese sostén moral.

Afectísimos servidores, Juventud Universitaria Católica.

f) Bernardo Monge O. f) Alberto Di Mare F. 
Señores del Consejo Universitario

La universalidad, que por su mismo nombre debe reunir toda la universidad, abarcando los diferentes aspectos humanos, ha traído consigo la costumbre tradicional en las más viejas y famosas instituciones europeas y americanas de una capilla contigua a los edificios, en la cual celebren los alumnos los actos oficiales de culto a Dios.

De esta costumbre, originada también por el hecho de haber sido la Iglesia la fundadora de las primeras casas universitarias, $y$ luego su perenne amiga a través de los siglos, no quiere apartarse nuestra Institución.

En prueba de ello profesores y alumnos pedimos al Consejo Universitario, con la mayor confianza, que en el planeamiento de nuestra Ciudad se considere la construcción de una Capilla dedicada al Santo y Sabio Patrono nuestro Tomás de Aquino, que sea un eslabón uniendo la Universidad de Costa Rica en el pasado siglo, con la del presente y que preste a todos un lugar tranquilo adjunto a las aulas, en el que pueda cada uno adorar a Dios, autor de la verdad que en ellas se estudia. Lugar para pedir a la Divinidad auxilio en la horas congojosas de los exámenes $y$ darle gracias luego por los favores recibidos. Lugar de reunión los domingos, en la misa universitaria, que ayude a constituir el Alma Mater $y$ deje un perenne recuerdo en cada joven, que llega en busca a la Universidad, no solamente de formación científica, sino de personalidad completa, armónica, plena de paz, y verdadera alegría. Juventud Universitaria Católica"

Agrega el señor Rector que, como viera que la solicitud de los estudiantes podría crear dificultades y conflictos, se dirigió a los promotores del proyecto a quienes pidió lo retirasen, por lo cual ellos le contestaron lo siguiente:
"Juventud Universitaria Católica.

Palacio Arzobispal

San José. 18 Agosto, 1953.

Sr. don Rodrigo Facio.

Rector de la Universidad de Costa Rica.

\section{Estimado don Rodrigo:}

El compañero Alberto Di Mare nos informó de una conversación que tuvo usted en la cual supo los problemas que podría suscitar en el Consejo Universitario nuestra moción para que se incluya en los planos de la Ciudad Universitaria, una capilla.

Consideramos deber nuestro presentar las firmas recogidas, pues las posibilidades de discordia son sin motivo, ya que el Consejo en cierta manera representa a los universitarios que han emitido su opinión casi unánime en el asunto que tratamos, $y$ no hay razón ninguna para no resolver la ponencia que mayor respaldo ha tenido de parte de alumnos y profesores.

Reiteramos nuestra confianza en la ecuanimidad de los miembros del Consejo que los obligará, tal vez en algún caso aún en contra de su propio credo, a complacer a tan gran mayoría, que pide algo tan justo y sensato.

Sin embargo, si el Consejo desaprobara nuestro proyecto, cosa que ni siquiera queremos pensar, nuestra conciencia nos obligaría, como directores de este movimiento, a convocar a Asamblea Universitaria, para cuya convocatoria contamos con las firmas de muchísimos profesores.

Nos suscribimos atentos servidores suyos $y$ amigos, los miembros de la JUC, representados por Carlos Salazar, Presidente. 
$\diamond \quad$ Acta de la sesión del Consejo Universitario No. 131 del 24 de junio de 1954

Articulo 03. La Juventud Universitaria Católica dirige la siguiente carta:

"Juventud Universitaria Católica.-

Palacio Arzobispal-

13 de Junio de 1954.

Honorable Consejo Universitario.

La Juventud Universitaria Católica se complace en presentar a ustedes por medio de los señores delegados del Consejo Estudiantil, la solicitud muy respetuosa de que sea incluida en la distribución de las áreas de la Ciudad Universitaria, una Capilla católica para la atención espiritual de los universitarios.

La misión de la Universidad es poner al estudiante en condiciones de definir la naturaleza y fines de su propia existencia, por las razones superiores de la misma. La cultura no es sino el descubrimiento de los valores más elevados de la vida humana.

Las circunstancias actuales del mundo han colocado al hombre ante el dilema absoluto de decidirse por una concepción concreta espiritual de la vida, o por una concepción simplemente mecánica de la existencia.

Otras interpretaciones sólo serían concebibles como sistemas parciales, inconclusos, y que pretenden reducir la vida humana a un programa de conveniente desarrollo intrascendente.

La Religión no se refiere únicamente, sin bien son ellas el fin supremo, a las verdades de realidad sobrenatural. Todo cuanto el idioma clasifica como abstracto es de naturaleza y de procedencia exclusivamente espiritual, tomada esta palabra en su sentido clásico. La verdad, la conciencia, el derecho político, la justicia social, los conceptos psicológicos de la personalidad, la filosofía de la Democracia, todas las virtudes humanas etc. pertenecen, sin lugar a duda, al mundo extrafísico de lo espiritual. Todos estos elementos constituyen por sí, la cultura. La técnica de las ciencias físicas puede crear una civilización, es decir, un bienestar terreno. La cultura es la alta concepción de la vida humana, a través de aquellos valores de suprema categoría.

Todas las manifestaciones de la vida tienen sus causas originarias y próximas.

Reducir la alta educación universitaria al concepto utilitario y simplemente dialéctico es colocar al joven estudiante ante la indecisión y la duda.

La introspección ha puesto de manifiesto que ser humano no es, ni el creador de la verdad, ni su árbitro definitivo, y que al bien y el mal son superiores al valor concreto de la conciencia humana. Si ese estudiante llegara a pensar que el hombre es la razón suprema de todo y la medida de todas las cosas, se habría creado una generación autoidólatra.

Pero si en la conciencia se extinguiera la fe positiva en un Dios personal y supremo, razón de ser y finalidad última del hombre, este llegaría a precipitarse en un existencialismo negativo, destructor, desesperado o a divinizar la materia, que es la definición clásica del comunismo contemporáneo.

La educación es la creación de elevados estímulos a fin de que el estudiante asuma la doble responsabilidad que le cabe como individuo y como ente colectivo, es decir, que integre en su conciencia sus deberes terrenos y sus deberes espirituales. No se puede limitar al joven en un plano puramente antropológico, es decir, al hombre como fin de sí mismo. Dejarlo indeciso frente a los problemas agudos de la existencialidad, es cerrarle la visión integral que él debe llegar a poseer. En otras palabras, admitiendo que la Universidad no está obligada a una confesionalidad práctica, sí debe ella darle los medios a su estudiantado, para que éste adquiera percepción clara del sentido espiritual de la vida.

Ninguna institución humana puede negarle a Dios atributos $y$ derechos que le son inherentes. Es preciso darle al concepto "Dios" la maravillosa amplitud, la suprema perfección, la fuente eterna $y$ sustancial de la verdad $y$ del bien, del derecho $y$ del deber, que le asignan sus propias perfecciones. Es decir, el hombre, está en el deber sagrado de reconocerle a Dios, y no sólo mentalmente, sino también en sentido 
determinado, las manifestaciones de la fe, del amor sobrenatural, de la reverencia y del acatamiento. No se puede tener de Dios una tal idea sin rendirle el homenaje que merece.

La circunstancia histórica de que Costa Rica sea católica en su mayoría es un bien que no debe menospreciarse, $y$ es un don que debe cultivarse con toda solicitud. No sólo no ha causado ningún mal, sino que mucho bien ha hecho la Iglesia a la Patria. Precisa valorar ese haber de virtudes $y$ de conceptos, de amor al bien, sentido de justicia, de dignidad $y$ de libertad que la fe siembra y hace florecer en las conciencias.

Se cree que el estar la Capilla en la Ciudad Universitaria puede ser causa de molestias $y$ de discriminación en el seno de la población universitaria.

Pero, la mayoría de esa población es católica: lo confirma el plebiscito estudiantil previo a estas gestiones.

A nadie se obligará a participar en los actos de culto, y a ellos concurrirán sólo quienes a bien lo tengan, espontáneamente.

Quien concurre a estos actos religiosos evidencia que conserva $y$ aprecia esos asideros del espíritu que precaven, o rendimos del vicio, de la materialidad. Y los futuros profesionales $y$ clases directoras de la Nación nada mejor pueden hacer que conservar, esclarecer y acrecentar esas luces y esos estímulos superiores. El profesional necesita en forma y grado superiores esas normas y esos ideales.

Se cree que, así como se concede a los católicos su capilla, se habrá de concederlas a otras entidades religiosas.

Más, esas entidades son extrañas al ser histórico de Costa Rica. Se trata de núcleos que más bien tratan de perturbar la convivencia espiritual-religiosa del país. Fácil sería aportar hechos que lo prueban. División aún entre hogares y vecinos. Además, esas disidencias religiosas no pueden ofrecer nada mejor ni nada igual que lo que brinda la Iglesia Católica. La fisonomía social y jerárquica de la Iglesia ofrece ese aspecto de seriedad religiosa, de cuidado doctrinario $y$ de dignidad ritual, delineamientos que no posee ningún núcleo disidente.
Además se trata de números que no justifican capillas. Tienen sus fuentes económicas extranjeras que les permita construir edificios hasta en exceso. Multitud de salas $y$ capillas para pocas docenas de personas. La teoría protestante dice que su religión es individual, subjetiva, sin culto, sin sacerdocio ni magisterio. Ante estas condiciones, al protestantismo le basta con sus valores para comentar la Biblia.

Además la inclusión de capillas disidentes sería autorizar la campaña de desunión, de discordia y de confusión.

Por lo cual, la Juc tiene la seguridad de que el Consejo Universitario, con el tacto que lo califica, despachará negativamente esas solicitudes de segunda intención.

Por la Juventud Universitaria Católica saluda a los señores Decanos.

\section{f) Bernardo Monge}

Presidencia desde el 11 junio de 1954.

Posdata: no es inoportuno ofrecer una visión resumida del artículo 76 de la Constitución de Costa Rica".

Establece esta regla jurídica que la religión católica es la del Estado.

Nota del autor: por ley 4764 del 17 de mayo de 1971, se derogó el artículo constitucional 75 , pasando el numeral 76 de la religión, al número 75 .

"El criterio de algunos es el de que el Estado no ha de tener religión. Entendemos por Estado al pueblo costarricense organizado en Instituciones y presidido por el gobierno civil.

El elemento formal, $y$ principal por lo tanto, es aquella población, ella es el objeto y el sujeto. El gobierno es el administrador de los intereses comunes. Pero el gobierno no es la fuente del derecho. Este es la consignación escrita de lo histórico del pueblo. Por cuanto este pueblo es el elemento formal y el objeto $y$ sujeto del derecho y parte sustancial del Estado, no se puede decir que el Estado no puede tener religión. Esta afirmación equivaldría a 
decir que el pueblo costarricense no es católico. Si el catolicismo costarricense ha sido y continúa siendo el sustento de la conciencia del país, el Estado costarricense es católico. Reducir el concepto de Estado a los organismos de gobierno es establecer la más clásica de las dictaduras.

Mucho mejor que nosotros, estudiantes, saben los señores catedráticos que la concepción actual de gobierno es el servicio de éste a favor de población costarricense. Todas nuestras instituciones de seguridad social no son sino el acatamiento de los organismos de gobierno a los derechos de la Nación".

Agrega el artículo constitucional 76: "Sin impedir el libre ejercicio de otros cultos".

"Esta justa protección a las minorías de ninguna manera puede tener el sentido positivo del miembro principal de la oración. Este consigna el hecho demográfico e histórico de que la religión católica es la del Estado. Y el segundo miembro protege de toda violencia a los otros cultos.

Conceder iguales derechos que a la religión católica a estos otros cultos es violentar el sentido natural de la oración, y es destruir por su base el pensamiento jurídico de este canon.

La disposición de amparo es una regla de respeto, pero no una extensión positiva de beneficios iguales.

Para servir a Dios y a los señores del Consejo Universitario.

f) Bernardo Monge. - Presidente de la JUC".

C) POSICIÓN DE LA CONTRALORÍA GENERAL DE LA REPÚBLICA

$\diamond \quad$ Acta de la sesión No. 168 del 20 de diciembre de 1954.

Artículo XXIV:

El Sr. Rector informa que consultó a la Contraloría General de la República, según fue acordado, el negocio de traspaso a la Juventud Universitaria Católica del lote de la Ciudad Universitaria. La Contraloría contesta así:
"15 de diciembre de 1954

Señor Lic. Rodrigo Facio Brenes

Rector de la Universidad de Costa Rica S.D

Estimado señor Rector:

Nos referimos a su atenta nota $\mathrm{N}^{\circ} 673-54$ de 14 de diciembre de 1954, en relación con la venta a la Asociación de la Juventud Universitaria Católica de una parcela, que desea hacerle esa Institución.

Con el mayor interés y dentro de la brevedad requerida, hemos estudiado el caso llegando a la conclusión de que la única manera como se podría lograr el fin deseado es sometiéndolo a la Asamblea Legislativa.

De usted con toda consideración, nos suscribimos atentos y seguros servidores.

Contraloría General de la Republica

f) Amadeo Quirós Blanco.- Contralor General”.

Se acuerda preparar un proyecto (de ley) de carácter general que cobije totalmente el acuerdo del Consejo sobre ventas de terreno con objeto de edificar para el culto religioso de los estudiantes $y$ profesores.

D) LA JUVENTUD UNIVERSITARIA CATÓLICA, JUC, COMUNICA

$\diamond \quad$ Acta de la sesión No. 736 del 21 de marzo de 1955

"Estimado señor: Conocedores de las gestiones que hizo la Universidad ante la Contraloría General de la República, para obtener permiso de venta del lote destinado a la construcción de la Capilla Universitaria, y de la respuesta dada por ese organismo, los miembros de la JUC hemos meditado una solución satisfactoria que evite la necesidad de una ley del Congreso, que de seguro renovaría las discusiones públicas.

Creyendo haber encontrado esa solución, en fecha reciente la presentamos al señor Contralor para conocer su opinión, y él nos prometió pasarla a estudio del Departamento Legal y así informado enviarnos su respuesta. 
Nuestro deseo es obtener un permiso para que la Universidad pueda sacar a licitación el terreno de la Capilla en una forma parecida a la siguiente:

La Universidad acepta propuestas para la venta de un lote limitado por las líneas $1234 \ldots$ en los planos de la Ciudad Universitaria, para la construcción de una Capilla Católica Apostólica y Romana, destinada al uso de los estudiantes, profesores y egresados de la Institución, etc.

Solicitamos por este medio al Consejo que estudie esta forma de venta, $y$ en cuanto nosotros recibamos la respuesta de la Contraloría la remitiremos al Sr. Rector.

Por la Juc, f) Flor de María Villalón".

En vista de lo anterior, se acuerda retener el proyecto de ley hasta tanto la JUC informe sobre el resultado de sus gestiones ante la Contraloría, para entonces tomar una decisión definitiva al respecto.

\section{OTRA COMUNICACIÓN DE LA JUVENTUD \\ UNIVERSITARIA CATÓLICA (JUC)}

"Palacio Arzobispal. San José, Costa Rica.

15 de abril de 1955

Sr. Don Amadeo Quirós B.

Contralor General de la República. S.D

\section{Señor Contralor:}

Como es de su conocimiento el Consejo Universitario ha resuelto vender un lote en la Ciudad Universitaria, para que en él se construya una Capilla Católica, en la cual los universitarios puedan celebrar los oficios litúrgicos con que nuestra religión rinde culto a Dios nuestro Señor.

En conversación que representantes de nuestra asociación, Juventud Universitaria Católica, tuvieron el gusto de tener con usted, le fueron expuestas las razones que nos inclinan - para evitar mayores molestias a nuestra Alma Mátera tratar de lograr que la compraventa indicada se realice mediante licitación y no por ley.

Por la presente tenemos el gusto de proponer a usted las razones por las cuales creemos que, de acuerdo con la legislación vigente, es absolutamente innecesario el acudir al trámite legislativo a fin de que se pueda enajenar a favor nuestro el mencionado terreno.
La Ley de Administración Financiera de la República, LAFR, establece, en su artículo 109:

"Salvo disposición especial en contrario, la compra, la venta o el arrendamiento de bienes estarán sujetos a las siguientes condiciones:

1) Cuando el valor de la operación sea igual o inferior a cinco mil colones se podrá hacer administrativamente en la forma que lo disponga el reglamento interior de la institución;

2) Cuando el valor de la operación sea superior a cinco mil colones pero inferior a diez mil deberá existir licitación privada;

3) Si el valor dicho es superior a diez mil colones deberá existir licitación pública.

4) En los casos en que las Instituciones Autónomas o las Corporaciones Municipales se encuentren imposibilitadas para sacar a licitación la compra de artículos en virtud de que, por su propia naturaleza o uso, si lo sean ofrecidos por un vendedor, o requerir seguridades que únicamente sean garantizadas por casas o entidades determinadas, serán adquiridos de ese vendedor, casa o entidad, previa autorización del contralor General de la República”.

En las disposiciones anteriores, se indica de modo claro y expreso que para enajenar bienes (muebles o inmuebles, pues no cabe distinguir donde la ley no distingue) el trámite indicado es el de la licitación pública o privada, según el caso; por lo cual ha de rechazarse de plano el criterio sustentado por el Consejo Universitario de obtener autorización legislativa para proceder a la venta, ya que ello equivale, en algún sentido $y$ hasta cierto punto, a violación de las disposiciones expresas de la Ley de Administración Financiera de la República, que ha sido dada por el legislador precisamente para hacer salir de su órbita - aceptando así muy convenientes principios de división del trabajo que le permiten dedicar su actividad a más altos ministerios $y$ hacen posible la eficiente labor de los poderes públicos-, la realización y contraloría de una serie infinita de actos administrativos. 
El único problema que plantea la solución anterior se refiere a la naturaleza misma de la licitación pública — aceptado de previo que el precio de la venta sea superior a diez mil colones, cosa aún no discutida- que en sí entraña la idea de proposición a varios, condición que no se satisface en el caso presente. Sin embargo, la misma Ley de Administración Financiera ha resuelto el punto en forma clara y terminante, mediante el inciso 4) del artículo 109 arriba citado; inciso que - para reforzar nuestra tesis - fue producto de una reforma a la ley original. En razón de que en la citada ley no se establecen normas más onerosas para la enajenación que para la adquisición de bienes, pueden aplicarse las disposiciones del citado inciso - relativas a la compra- para la venta, mediante razonamiento analógico. El asunto que discutimos es precisamente el de una sola entidad, la Iglesia Católica, con interés en ofrecer $y$ con capacidad de rendir seguridades $y$ garantías de un debido uso.

Asimismo el artículo 92 (el subrayado es nuestro) de la Ley de Administración Financiera dispone expresamente: "Cualquier venta que realicen las dependencias oficiales se hará a través de la Proveeduría Nacional y por medio de licitación pública. En caso de que la licitación resultare infructuosa o inconveniente, se usará el remate".

En nuestro caso se trata de una venta, que cae por tanto dentro del concepto de cualquier venta que la ley establece; no puede resultar infructuosa puesto que hay la seguridad de que se presentará por lo menos un comprador. Pero nótese que la ley, en la hipótesis de que la licitación resultara infructuosa, o inconveniente - caso más grave aún-, no acude a la autorización legislativa; sino al trámite subsidiario del remate. Aún cuando no es este el artículo, ni el trámite aplicable a nuestro negocio, lo aducimos para demostrar que el espíritu del legislador no podía haber sido más claro respecto de retirar de su esfera de acción el conocimiento de estos actos; someterlos a su conocimiento es incurrir en un entrabamiento de las funciones de los Poderes Públicos, a todas luces inconveniente y contrario al espíritu del ordenamiento jurídico vigente.
Finalmente, para mayor abundamiento de razones, la ley quiso resolver, expresamente, el caso que en cuestión consideramos y lo hizo mediante la reforma que se introdujo al texto original de la Ley de Administración Financiera, a la cual se agregó un párrafo (que constituyen actualmente los párrafos segundo y tercero) en su artículo 96, que a la letra dice:

"Sin embargo, cuando esas operaciones se realicen con entidades o corporaciones, nacionales o extranjeras, de utilidad pública o de bien social, generalmente reconocidas como ajenas al espíritu de lucro, o con empresas o entidades que por razones especiales no pueden entrar en licitaciones, - -el subrayado es nuestro- pero cuyo afán es el de ayudar al Estado, podrán hacer libremente $y$ hasta por la suma de cien mil colones (100 000,00 colones), obteniéndose de previo la anuencia del Ministerio de Hacienda y la autorización del Contralor General de la República.

En los casos del párrafo anterior, la Proveeduría Nacional deberá anunciar en el Diario Oficial las condiciones de la operación que se propone realizar, otorgando un plazo de quince días para oír las objeciones o proposiciones que otros interesados pudieran hacer, $y$ en caso de que se produzcan ofertas en condiciones iguales o más ventajosas para el Estado, se procederá a una licitación pública. Si no hubiere objeción o proposición dentro del plazo indicado, la Proveeduría Nacional emitirá la orden de compra o pago correspondiente, con lo cual quedará firme la operación". (Nota del autor: asî reformado por Ley Nro. 1478 del 17 de julio de 1952, La Gaceta Nro. 166).

No cabe ninguna duda respecto de que la Iglesia Católica como la Juventud Universitaria Católica, reúnen los requisitos de la hipótesis jurídica que ha motivado las disposiciones anteriores y por ello el procedimiento a seguir debe ser el indicado en el artículo transcrito (de acuerdo con las disposiciones del artículo 111 de la Ley de Administración Financiera, que hace extensivo a las Instituciones autónomas las regulaciones mencionadas).

Por tanto, la Universidad podrá vender directamente, sin licitación, y publicará luego la licitación para constatar si existe mejor postor. 
Nótese que la ley se refiere no solo a nuestro caso, un solo posible interesado en la operación, sino a uno mucho más extremado, sea, el de que no haya ningún posible participante en la licitación, al mencionar a "empresas o entidades que por razones especiales no pueden entrar en licitaciones".

Creemos, por tanto, que es evidente - de seguirse el procedimiento por nosotros solicitado- que la Contraloría no estaría invadiendo campos reservados a la Asamblea Legislativa, ni incurriendo en procedimientos errados en lo relativo a formalidades de las licitaciones, sino cumpliendo estrictamente con el espíritu y la letra de la ley.

Finalmente, para mayor abundamiento, el artículo 182 de la Constitución Política establece claramente que:

"Los contratos para la ejecución de obras públicas que celebren los Poderes del Estado, las Municipalidades y las instituciones autónomas, las compras que se hagan con fondos de esas entidades $y$ las ventas o arrendamientos de bienes pertenecientes a las mismas, se harán mediante licitación, de acuerdo con la ley en cuanto al monto respectivo".

Se establece así, terminantemente, la obligación del procedimiento de licitación, pero se exceptúa el de autorización previa por parte de la Asamblea Legislativa.

En nuestra conversación con usted, nos manifestó el escrúpulo que sentía de autorizar el trámite por nosotros solicitado, pues le parecía que ello equivaldría a invadir un campo reservado por nuestro ordenamiento jurídico a la Asamblea Legislativa. Respetuosamente indicamos que a nuestro modo de ver, ello obedece a una generalización indebida del procedimiento establecido - probablemente, ya que no tenernos ante nosotros las leyes en cuestión- por las Ordenanzas Municipales, para la enajenación de bienes pertenecientes a los municipios, en que se requiere la previa autorización legislativa. De acuerdo con la legislación que hemos tenido ante nuestros ojos, $y$ con las razones en la presente aducidas, no parece procedente mantener las dudas que tanto ustedes como nosotros experimentábamos en nuestro mencionado cambio de impresiones; excepto claro está, que leyes especiales por nosotros no contempladas dispusieran de diferente manera.

Le rogamos estimar la presente como una petición de derechos que nuestra asociación atentamente solicita, a fin de que se le reconozcan en el negocio en cuestión, todas las prerrogativas que a la Iglesia corresponden, de acuerdo con el artículo 96 de la Ley de Administración Financiera.

Agradeciendo la atención que se sirva prestar a la presente, así como sus reiteradas muestras de simpatía y de estímulo por la labor que en el presente asunto ha realizado nuestra asociación, aprovecho la oportunidad para suscribirme - en nombre la Juventud Universitaria Católica - atenta y segura servidora,

Flor de María Villalón G, Secretario (sic)”.

E) POSICIÓN DEL ABOGADO DE LA UNIVERSIDAD DE COSTA RICA

४ Acta de la sesión Nro. 808 del 26 de marzo de 1956

Nota del autor: el abogado de la Universidad de Costa Rica, don Rogelio Sotela, se refiere al documento de la JUC del 15 de abril de 1955, en este artículo XLVIII.

Artículo XLVIII. -Se toma nota del informe que literalmente dice:

"San José, marzo 16 de 1956

Sr. Don Rodrigo Fournier

Oficial Mayor de la Rectoría Pte.

Señor Oficial Mayor:

Con referencia a la comunicación de 15 de abril de 1955, remitida por Juventud Universitaria Católica al señor Contralor de la República, cuya copia se me transcribió para informar sobre la base legal de la gestión que en ella se realiza, tengo el gusto de manifestar lo siguiente: 
En mi concepto no es posible proceder a la venta por licitación de un lote para la Iglesia Católica o la Juventud Universitaria Católica con la finalidad de construir una capilla católica, dentro de los terrenos de la ciudad universitaria.

La licitación no podría hacerse así en esa forma tan específica, porque lo impediría la concurrencia de postores o licitantes. Sería una licitación para un solo comprador, lo cual va contra "el espíritu" de la Ley de la administración financiera de la República. Esa licitación podría hacerse únicamente en forma abierta: venta de un lote. Pero claro está que realizarla en esa forma podría ocasionar graves inconvenientes a la Institución ya que podría en definitiva resultar adjudicatario quien no pretenda erigir allí una capilla, sino destinar el terreno a otros usos, o bien un culto diverso del católico. Además, no creo que pueda la Universidad, sin tropezar con su organización jurídica, hacer ventas para usos de esa índole, porque dentro del Estatuto Universitario hay disposiciones que impelen a la Universidad a difundir las letras, las ciencias y las artes, pero no los credos religiosos. Además, habría que establecer previamente el lugar donde se piensa ubicar, ya que si fuera en parte de alguna de las fincas expropiadas, su venta seria imposible dado que la adquisición fue, según se dice en los Decretos respectivos y en la sentencia dada por los Jueces, "para construir la ciudad universitaria" y no para otros fines.

La cita del inciso 4) del artículo 109 (de la Ley de la administración financiera de la República, LAFR) que se hace en el memorial referido no es de aplicación, porque esa disposición se refiere al caso en que las instituciones autónomas vayan a comprar, no a vender.

La del artículo 96 LAFR, no cambia la situación porque aunque fuera privada, siempre sería una licitación, que en los términos restrictivos propuestos, cree el suscrito que no puede ser realizada; $y$ el artículo 92 de la LAFR, no es aplicable a las instituciones autónomas de acuerdo con el 111 idem, pero aunque lo fuera, el remate que se supone es todavía menos propicio que todo el trámite anterior para llegar a la finalidad que se persigue.
Atentamente,

Rogelio Sotela, asesor legal de la Universidad de Costa Rica".

Observamos dos aspectos que sobresalen en este tema de la construcción de la capilla católica en el campus de la Universidad de Costa Rica:

1) El terreno para construir la capilla católica, dentro de la ciudad universitaria, la Universidad no lo vendió a la Juventud Universitaria Católica o a otra persona.

2) La capilla no se construyó.

Fue una gestión interesante, que puso de manifiesto un conjunto de argumentos religiosos, sociales y jurídicos llamativos. (Deseo dejar constancia de mi agradecimiento a la funcionaria de la Unidad de Información del Consejo Universitario Br. Laura Cristina Morales Jiménez, por la valiosa colaboración que me prestó localizando las actas y documentos del citado Consejo, de los años 1953 a 1956).

\section{EL DELITO DE ABORTO}

También, me refiero a este tema del aborto que don Rodrigo Facio Brenes analizó a los 22 años, con fecha de terminación: el 20 de setiembre de 1939, siendo estudiante del cuarto año de la carrera de Derecho y que este autor lo redactó para ser presentado en el VIII Congreso Panamericano del Niño. Se iba a celebrar en San José, Costa Rica, ese VIII Congreso, en octubre de 1939; pero - como lo informa el propio Facio Brenes en esta investigación- se trasladó a Washington DC, del 2 al 9 de mayo de 1942, debido al estallido de la II Guerra Mundial.

Siendo ya Facio Brenes, abogado y profesor de la Facultad de Derecho, como se explica en este artículo, el Patronato Nacional de la Infancia da a conocer este estudio. Esta investigación tiene 125 páginas.

Debido a que el aborto sigue siendo un tema polémico $y$ en este sentido con plena actualidad, hago esta breve presentación de la investigación hecha por el autor de cita. 
El tema I: protección a la salud y asistencia médica, era al que correspondía la ponencia citada al Congreso indicado.

Tanto en el resumen (pp. 1 y 2) como en la explicación necesaria (p. 4) de la investigación, se desprende que su autor no asistió a la reunión de Washington DC en 1942. He mantenido la tipografía que usó Facio Brenes para escribir el índice de este trabajo.

\section{A) POSICIÓN DE RODRIGO FACIO BRENES}

El índice de esta investigación es:

EXPLICACIÓN NECESARIA. PATRONATO NACIONAL DE LA INFANCIA

1. PROPÓSITO

2. FIGURA JURÍDICA DEL ABORTO.

a) En busca de un concepto global de lo que en Derecho deba tenerse por aborto.

b) Sentido etimológico y limitación Jurídica.

c) La cuestión de la época del embarazo.

I. Distinción de la ciencia médica.

II. La cuestión teleológica de la animación.

III. La ley rusa.

IV. La tesis jurídica que priva actualmente.

d) Escogiendo entre las nociones de violencia, prematuridad $y$ artificialidad.

e) Requisito del feto vivo y regularmente constituido.

f) La cuestión de la expulsión.

g) Supervivencia de la criatura expulsada.

h) Una fórmula práctica en interés de la técnica médico-legal.

3. ¿ES UN DELITO EL ABORTO?

a) ¿Qué es delito?

I. Concepto formal.

II. El delito a través de los autores y tratadistas.

III. Resumen histórico: el delito en función social.

b) ¿Constituye el feto un interés individual o colectivo digno de protección legal?
I. El feto como interés demográfico.

II. El feto como interés familiar.

III. El feto como interés privado de la madre.

IV. El feto como interés vital individual.

4. PROBLEMAS PRÁCTICOS RELACIONADOS CON LA PUNIBILIDAD DEL ABORTO.

a) La defensa de la vida y la salud de la madre. I. Demanda de punición.

II. Demanda de impunidad.

b) La ineficacia y la falta de equidad de la sanción legal.

c) Necesidad del descenso de la pena.

d) ¿Conviene castigar la tentativa?

5. SIETE MOTIVACIONES DEL ABORTO.

6. ABORTO TERAPEÚTICO

a) El problema: conflicto entre las vidas de la madre y el feto.

b) Opinión social y razones humanas.

c) Opinión doctrinaria y razones jurídicas.

d) La posición de la Iglesia Católica.

e) Concretando la figura del aborto necesario.

I. Preservación de la vida solamente o también de la salud materna.

II. ¿A quiénes debe amparar la impunidad?

III. La cuestión del consentimiento.

7. ABORTO POR RAZONES EUGENESICAS

a) Tendencia socialista de la ciencia jurídica de hoy.

b) El aborto eugenésico y las consideraciones humanitarias.

c) La Iglesia Católica.

d) El problema de la herencia.

e) Soluciones legislativas.

f) Requisitos necesarios.

I. Intervención de un médico

II. El consentimiento de los padres.

8. ABORTO POR RAZONES SENTIMENTALES

a) La cuestión del nombre.

b) La opinión social y las razones humanas.

c) Los tratadistas y las razones jurídicas.

d) Definiendo el aborto por conflicto psicológico. 
I. La violación como única y constante fuente del delito.

II. Necesaria distinción en cuanto al requisito del consentimiento.

III. Impunidad del aborto y castigo de la violación.

IV. El requisito del médico titulado.

\section{ABORTO HONORIS CAUSA}

a) La heroína, un producto de la ignorancia sexual.

b) El concepto de la honra, como valoración $y$ perjuicio social.

c) Desvalidez de la madre soltera, fruto de imprevisiones legales.

d) Examen de la irresponsabilidad relativa en el embarazo.

e) Se debe atenuar o conservar el actual rigor de la pena.

f) ¿Conviene la impunidad?

g) Eliminación de las causas.

I. Educación sexual.

II. Modificación del concepto social de la madre soltera.

III. Reformas a la legislación.

h) Amplitud de la figura jurídica del aborto honoris causa

\section{ABORTO NEO MALTHUSIANO}

a) Malthus.

b) Solución automática de la desproporción entre las bocas y el pan.

c) El aborto por miseria.

d) Eliminación de las causas.

I. Castidad.

II. Birth control.

III. El método del doctor Ogino.

IV. Más elevados niveles de vida.

e) Atenuación de la pena ordinada.

f) Figura Jurídica del aborto por miseria.

I. Consentimiento.

II. Sujetos del delito.

11. ABORTO EN EJERCICIO DEL DERECHO A UNA MATERNIDAD CONSCIENTE

a) La mujer célibe.

b) Ilicitud del aborto realizado en ejercicio del derecho a una maternidad consciente.
I. Contra la anarquía sexual.

II. La mujer célibe posee medios para evitar al embarazo.

III. Poca frecuencia de tal clase de aborto.

c) Necesidad de una rectificación del feminismo radical.

12. CONCLUSIÓN

NOTAS (son 132)

Nota del autor: el ginecólogo japonés

Kyusaku Ogino (1882-1975), desarrolló

el método sobre los ciclos menstruales, control de la natalidad del ritmo o del calendario. Por su parte el médico austriaco Hermann Knaus (1892-1970), lo perfeccionó.

En las conclusiones de esta investigación, el autor afirma, que con vistas a una reforma legal:

$\diamond \quad$ El aborto puede ser sancionado penalmente.

$\diamond \quad$ La tentativa de aborto no es punible, salvo cuando se ejecutare por la propia embarazada y ésta hubiere sido condenada anteriormente por aborto consumado, frustrado o intentado, o por tercera persona que tuviere iguales antecedentes judiciales o efectuado la tentativa persiguiendo lucro.

$\diamond \quad$ Están exentos de responsabilidad penal:

1. La mujer que causare o permitiere su aborto y los que, sin haber mediado su negativa, "lo provocaren" para salvar su vida, de ella;

2. El médico que provocare el aborto de una "mujer demente o idiota";

3. La mujer que permitiere su aborto y el médico que con su consentimiento, o con el de sus representantes legales, ratificado por el Patronato Nacional de la Infancia; "si se trata de una menor de doce años, lo provocare, cuando el embarazo haya sido producido por una violación" (p. 125). 


\section{CÓDIGO PENAL COSTARRICENSE VIGENTE Y ACTUAL}

Actualmente, el Código Penal vigente regula el aborto de la siguiente manera:

Artículo 118.- Aborto con o sin consentimiento:

El que causare la muerte de un feto será reprimido:

1) Con prisión de tres a diez años, si obrare sin consentimiento de la mujer o si ésta fuere menor de quince años. Esa pena será de dos a ocho años, si el feto había alcanzado seis meses de vida intrauterina.

2) Con prisión de uno a tres años, si obrare con consentimiento de la mujer. Esta pena será de seis meses a dos años, si el feto no había alcanzado seis meses de vida intrauterina.

En los casos anteriores se elevará la respectiva pena, si del hecho resultare la muerte de la mujer.

Artículo 119.- Aborto procurado.

Será reprimida con prisión de uno a tres años, la mujer que consintiere o causare su propio aborto. Esa pena será de seis meses a dos años, si el feto no había alcanzado seis meses de vida intrauterina.

\section{Artículo 120.- Aborto honoris causa.}

Si el aborto hubiere sido cometido para ocultar la deshonra de la mujer, sea por ella misma, sea por terceros con el consentimiento de aquélla, la pena será de tres meses hasta dos años de prisión.

Artículo 121.- Aborto impune.

No es punible el aborto practicado con consentimiento de la mujer por un médico o por una obstétrica autorizada, cuando no hubiere sido posible la intervención del primero, si se ha hecho con el fin de evitar un peligro para la vida o la salud de la madre y éste no ha podido ser evitado por otros medios.
Artículo 122.- Aborto culposo.

Será penado con sesenta a ciento veinte días de multa, cualquiera que por culpa causare un aborto.

El tema del aborto es polémico y por lo tanto, genera una cantidad de opiniones $y$ de puntos de vista.

La investigación que realizó Facio Brenes es relevante y es un aporte bien documentado, en su época, a esta temática.

Aborto: pérdida de la concepción antes de alcanzar la viabilidad extrauterina (Juan Ignacio Alonso, director editorial, Diccionario de Medicina, Facultad de Medicina, Universidad de Navarra. Madrid. Editorial Espasa Calpe, 1999: 4).

En la actualidad, la tendencia mayoritaria es a estimar que el aborto:

$\diamond \quad$ No es punible el aborto practicado por un médico en centro sanitario público privado y con consentimiento de la mujer embarazada, siempre y cuando exista un peligro para la vida o salud física o psíquica de la embarazada.

$\diamond \quad$ Además está despenalizado cuando el embarazo sea consecuencia de un hecho constitutivo de delito de violación, siempre y cuando este se practique dentro de las 12 primeras semanas de gestación y cuando se presuma de que el feto habrá de nacer con graves taras físicas o psíquicas, siempre que el aborto se practique dentro de las 22 primeras semanas de gestación (García-Orellán, Rosa y Ortega, Susana. "El aborto: poder y manipulación de conceptos en el cuerpo de la mujer". Ideología y género. Tomo II. Universidad de Navarra-Promesa Cultural, 2011: 175).

\section{CONCLUSIÓN}

Sin duda, el contenido del archivo personal de don Rodrigo Facio Brenes, contiene 
valiosa información profesional, académica, de investigación, periodística y fundamentalmente humana. El perfil de este ser humano atrayente y sugestivo, queda probado con este archivo que él fue elaborando día a día, documento a documento, palabra por palabra. Fue un Maestro en todo sentido, siendo sus enseñanzas para mí, una fuente de inspiración y de motivación para edificar mi propio trabajo. Por todo ello, le estoy sumamente agradecido.

Fecha de ingreso: 09/07/2012 Fecha de aprobación: 10/08/2012 